\title{
Genomic Breeding of Green Super Rice Varieties and Their Deployment in Asia and Africa
}

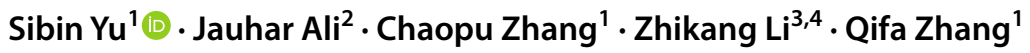

Received: 12 November 2019 / Accepted: 17 December 2019 / Published online: 8 January 2020

(c) The Author(s) 2020, corrected publication 2020

\begin{abstract}
Key message The "Green Super Rice" (GSR) project aims to fundamentally transform crop production techniques and promote the development of green agriculture based on functional genomics and breeding of GSR varieties by whole-genome breeding platforms.

Abstract Rice (Oryza sativa L.) is one of the leading food crops of the world, and the safe production of rice plays a central role in ensuring food security. However, the conflicts between rice production and environmental resources are becoming increasingly acute. For this reason, scientists in China have proposed the concept of Green Super Rice for promoting resource-saving and environment-friendly rice production, while still achieving a yield increase and quality improvement. GSR is becoming one of the major goals for agricultural research and crop improvement worldwide, which aims to mine and use vital genes associated with superior agronomic traits such as high yield, good quality, nutrient efficiency, and resistance against insects and stresses; establish genomic breeding platforms to breed and apply GSR; and set up resource-saving and environment-friendly cultivation management systems. GSR has been introduced into eight African and eight Asian countries and has contributed significantly to rice cultivation and food security in these countries. This article mainly describes the GSR concept and recent research progress, as well as the significant achievements in GSR breeding and its application.
\end{abstract}

Communicated by Lixi Jiang.

Sibin Yu and Jauhar Ali have contributed equally to this work.

Electronic supplementary material The online version of this article (https://doi.org/10.1007/s00122-019-03516-9) contains supplementary material, which is available to authorized users.

Zhikang Li

zhkli1953@126.com

Qifa Zhang

qifazh@mail.hzau.edu.cn

1 National Key Laboratory of Crop Genetic Improvement, Huazhong Agricultural University, Wuhan 430070, China

2 International Rice Research Institute, DAPO Box 7777 Metro Manila, Philippines

3 Institute of Crop Sciences, Chinese Academy of Agricultural Sciences, Beijing, China

4 College of Agronomy, Anhui Agricultural University, Hefei, China

\section{Introduction}

Rice (Oryza sativa $\mathrm{L}$.) is one of the most important food crops and is the primary staple food for nearly half of the world's population. It is expected that the world population will continue to grow and exceed nine billion by 2050, which demands a nearly $70 \%$ increase in food production (FAO 2013; http://faostat.fao.org/). Hence, increasing rice yield is critical to ensuring the world food security and living standards of everyone. The breeding and cultivation of semidwarf rice and hybrid rice varieties have contributed to two great leaps in rice productivity (Khush 2001). However, the breeding and wide adoption of many semi-dwarf, fertilizerresponsive/tolerant, and high-yielding varieties have also caused the overuses of chemical fertilizers, pesticides, and water resources (Hazell et al. 1986). Particularly in Asia, the overuse of pesticides has caused severe damage to ecological environments. The application of large amounts of nitrogenous fertilizers and the low fertilizer-use efficiency have led to problems of severe soil degradation and eutrophication of water bodies. The shortage, low fertilizer-use efficiency, and uneven distribution of water resources have caused a series of environmental problems such as the prevalence 
of drought (Zhang 2007). In addition, because of the frequent occurrences of extreme weather worldwide, the conflicts between agricultural production and environmental resources are becoming increasingly intense (Yorobe et al. 2016). Therefore, ensuring the food security and sustainable development of agriculture has become a key strategic concern worldwide.

Asia contributes significantly with $90 \%$ of global rice production and its consumption (Elert 2014). Hence, the conflicts between rice production and environmental resources are particularly acute. To enhance rice yields, farmers have gradually increased the application amounts of fertilizers to meet the demands of high-yielding varieties for more nitrogen (Ali et al. 2018). In recent decades, the average rice productivity in China rose from $2.1 \mathrm{t} \mathrm{ha}^{-1}$ in 1961 to $6.7 \mathrm{t} \mathrm{ha}^{-1}$ in 2013, which was accompanied with greatly increased application of nitrogen fertilizer from 8 to $35 \%$ of total amount of fertilizers used in the world (Wang and Peng 2017). The overuse of nitrogenous fertilizers and low fertilizer-use efficiency have caused large residual amounts of nitrogenous fertilizer to enter the soil and water bodies around farm lands, leading to severe environmental pollution (Peng et al. 2002; Ali et al. 2018). Also, the frequent occurrences of drought are another factor that hinders agricultural development, posing significant threats to world food security (Luo 2010). China suffers severely from water deficit, especially for agriculture, and is frequently hit by droughts. Since the 1990s, about 26 million hectares of its arable lands have been affected by drought every year, which directly led to a loss of 70 million tons in food crop production (Jing 2007). Meanwhile, the total irrigation water used for rice production accounts for nearly $70 \%$ of the total water amount used for agricultural production. This limited water resource can barely meet the demand for rice production in China (Zhang 2007). Hence, the breeding and cultivation of new types of varieties with superior resistances/tolerances to drought and pests, greatly improved water and nutrient (nitrogen and phosphorus) use efficiency, as well as highyield potential and desirable grain quality have become a crucial goal of rice improvement to increase and/or stabilize rice productivity, alleviate the water shortage, protect the ecological environments, and ensure food security of China.

\section{The GSR project and its major research themes}

Facing the increasingly severe resource shortage, environmental pollution, and degradation of ecological systems, Chinese scientists proposed the GSR project in 2005, which aims to develop new rice varieties with various green traits, including resistance to multiple insects and/or diseases, high use efficiency of fertilizers, water-saving, drought tolerance, and stress resistance on the basis of high grain yield and quality (Zhang 2007). Now, the GSR concept not only refers to new varieties with green traits but also represents the green "resource-saving and environment-friendly" conceptualization of crop breeding technology and "high-yielding, high-efficient, ecological, and safe" crop management systems (Zhang 2007; Wing et al. 2018). After the proposal of the project, it has been strongly supported by the Chinese Government and international funding programs. In 2009, the Bill and Melinda Gates Foundation funded the international cooperation project on "Green Super Rice for Resource-poor farmers of Africa and Asia" (OPP1130530). In 2010, the Ministry of Science and Technology of China granted the 863 Project, "Breeding and Development of Green Super Rice," with extended funding up to 2018 (2014AA10A600).

The GSR project has five main focuses (Zhang et al. 2018): (1) development and improvement of the theoretical and technical systems for GSR breeding. These systems and technologies were established at the population, individual, trait, and genome levels, and the strategies to combine the genomes and green traits of various germplasm resources for breeding of the GSR varieties proposed; (2) establishment of whole-genome selection platforms based on the recent developments/findings in the rice functional genomics research worldwide, including whole-genome breeding databases for molecular-designed breeding and gene chips; (3) development of new germplasm resources by pyramiding of genes of green traits, including development of novel germplasms with improved resistances to multiple abiotic (primarily drought) and biotic stresses, high water and nutrient-use efficiencies, and high grain yield and quality; (4) breeding of new GSR cultivars (both inbred and hybrid) with various combinations of green traits, improved grain yields and quality; (5) high-yield cultivation and field management techniques for GSR. The techniques and criteria for assessing green traits were established. In addition, "resourcesaving and environment-friendly" cultivation management systems were set up and GSR varieties were widely planted. According to the GSR concept, we tentatively define newly developed GSR cultivars for a specific target rice ecological area into one of the following 4 main types: (1) water-saving and drought-resistant (WDR) cultivars that have the same or better grain yield and quality as the current check varieties under the normal irrigated conditions but yield $30 \%$ or more under the water-deficit or drought conditions; (2) nutrientuse-efficient (NUE) cultivars that show the same or better grain yield and quality as the current check varieties but with $30 \%$ of less fertilization (nitrogen and/or phosphorus) application; (3) pest-resistant cultivars that have significantly enhanced pest resistance to one or more key pests (with a $30 \%$ or more reduction in pesticide application); and (4) stress (salt, alkalinity, cold, heat, etc.)-tolerant cultivars that 
have the same or better grain yield and quality as the current check varieties under the non-stress conditions but yield 30\% or more than the checks under the stress conditions. In the program, GSR varieties to be developed may carry different combinations of the green traits depending on yield limiting factors in any specific environments.

\section{Genomic breeding for GSR}

Based on the concept of Green Super Rice with less inputs, more production, and a better environment, several breeding strategies for developing GSR cultivars were formulated by integrating germplasm accessions, genomic resources, and molecular technology and breeding tools (Zhang 2007; Ali et al. 2018; Wing et al. 2018). Germplasms are essential materials for the genetic improvement and functional genomics research of crops and are strategic resources to support the sustainable development of GSR as well. With a long planting history, rice is rich in genetic/genomic diversity with huge numbers of rice germplasm collections, including both cultivated species and its closely related wild species maintained in gene banks worldwide (Wing et al. 2018). With the rapid advancement of DNA-sequencing and multi-omics technology, whole-genome analyses of gene variations and genome diversity of different types of rice germplasm resources have become an essential part of rice germplasm characterization and utilization. These abundant rice germplasm resources provide sufficient materials for further dissecting the genetic basis of complex traits, identifying novel genes and their functions for future rice molecular breeding by design (Xie et al. 2015; Wang et al. 2015b, 2018a).

Based on the research advances in the rice functional genomics and genomic diversity, different genomics-assisted breeding strategies have been adopted for the development of the four major types of GSR cultivars (Wing et al. 2018). By combining multi-omics such as genomics, phenomics, epigenetics, metabolomics, proteomics, and transcriptomics, the desirable genes in the wild and cultivated rice species were mined and identified through large-scale and highthroughput phenotypic analyses on the re-sequenced rice germplasm (including wild species) accessions. A series of near-isogenic lines (NILs) or introgression lines (ILs) with the elite genetic backgrounds (widely planted major rice varieties and hybrid parents) that contain only small genomic segments (e.g., about $200 \mathrm{~kb}$ ) of target genes were created through the whole-genome selection platform (Fig. 1). This genome selection platform comprising specifically designed gene chips (Yu et al. 2014; Chen et al. 2014) and selection systems simultaneous selecting any specific groups of target genes, non-target ones, and the entire genome background, which is expected to facilitate the accurate manipulation and improvement of targeted green traits (Wing et al. 2018). Another strategy involves an introgression breeding scheme in which large-scale crossing and massive repeated backcrossing to one (or more) elite parent are performed to generate NILs with the desirable traits or genes (Fig. 2). Such NIL populations are coupled with genotyping and massive phenotyping to identify genetic variation associated with critical green traits. Then, pre-GSR lines or GSR varieties were developed in a two-stage process. In the first stage, elite lines carrying a single gene of interest were developed and thoroughly evaluated for the green traits, which by themselves were useful as pre-breeding GSR lines. Second, the genes introduced into these lines would be combined in a designed way to develop cultivars with favorable traits. The introgression breeding approach has been used for developing GSR, and demonstrates being robust in several successful applications (Li and Ali 2017; Feng et al. 2018; Liang et al. 2018), because of its advantage with simultaneous improvement and genetic dissection of complex traits by introgressing one or more target genes through the genome selection system. This approach resulted in many GSR varieties and their adoption across Asia and Africa in the IR64, Huanghuazhan (HHZ), and Weed Tolerant Rice 1(WTR1) recipient backgrounds (Ali et al. 2018).

\section{Green genes for the breeding of new GSR varieties}

Currently, more than 3000 genes affecting a wide range of phenotypes have been cloned and dissected in rice (up to 2018, www.ricedata.com; $\mathrm{Li}$ et al. 2018b; Wing et al. 2018). Of these cloned rice genes, those associated with resistance to biotic stresses (diseases and insect pests) and abiotic stresses (drought, salinity, flooding, low inputs), and traits of high nitrogen- and phosphorus-use efficiency, high yield, and good grain quality, are mostly "resource-saving and environment-friendly" and can be referred to as green genes. These green genes have been the targets for GSR breeding (Table 1).

One important component of the GSR project was to resequence a core collection of 3024 rice germplasm accessions and phenotype the sequenced lines and GSR parents plus a large set of chromosomal segment substitution lines (CSSLs) for many green traits to discover and mine genes/QTLs associated with the green traits by genome-wide association analyses. As a result, a large number of loci associated with green traits were identified (Sun et al. 2015; Zhu et al. 2015; Lv et al. 2016; Qiu et al. 2017; Liang et al. 2018). These newly detected QTLs or the cloned genes provide abundant genetic resources for the development of new GSR varieties.

To facilitate more efficient and accurate integration of the genotyping technology in GSR breeding, a pedigree analysis 


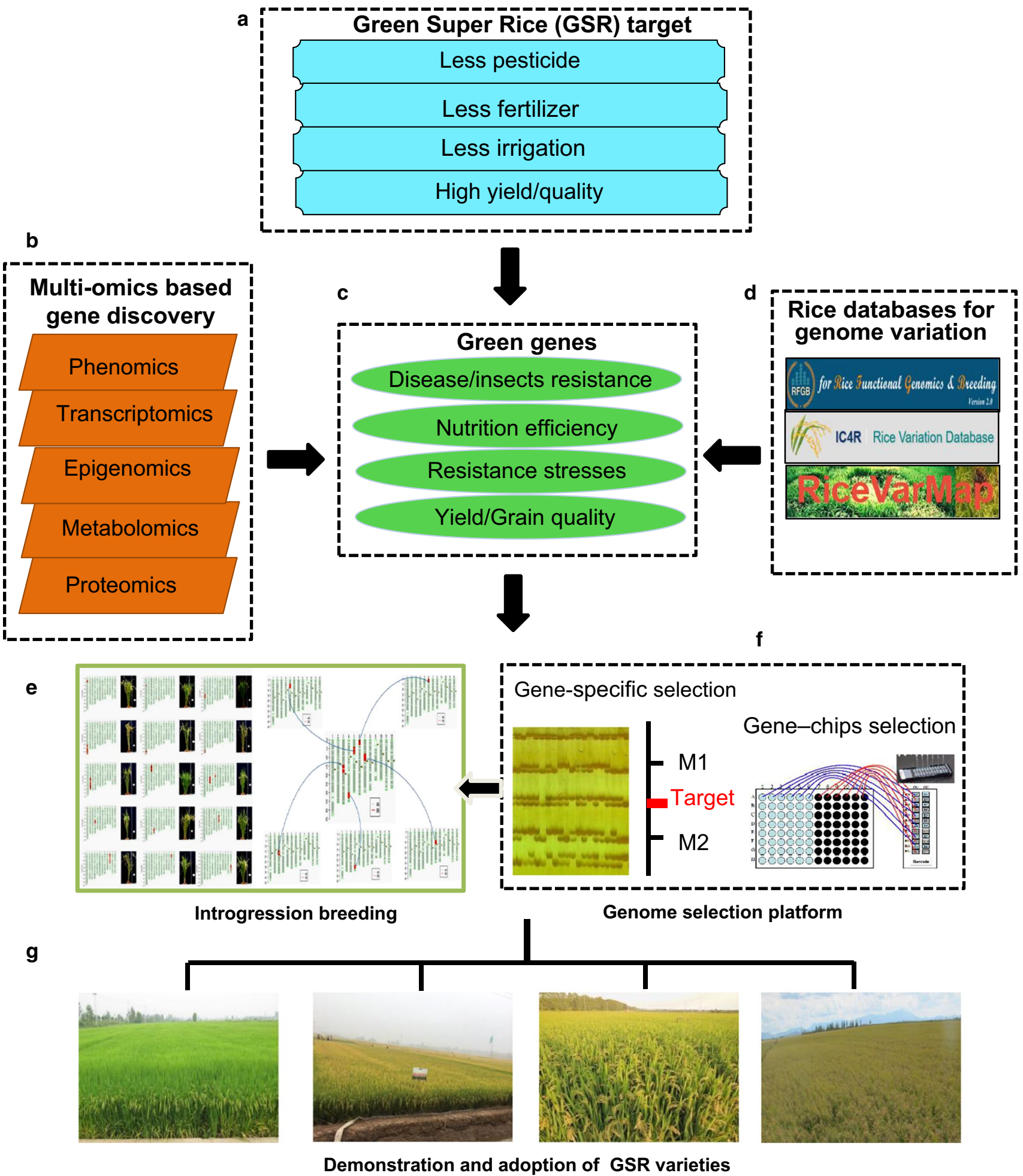

Fig. 1 The target, strategy, and design for the development of Green Super Rice (GSR). a The goal of GSR was proposed to promote sustainable rice production with less inputs, while still achieving a yield increase and quality improvement. b Integration of multi-omics (phenomics, genomics, transcriptomics, epigenomics, metabolomics, and proteomics) to identify and understand green genes (such as high yield, good grain quality, resistance to stresses, nutrient-use efficiency). c A series of databases for rice genomic variations. d Schematic illustration of introgression lines, each containing a target gene and that could be combined in various ways to develop GSR. e The rice gene-chip and the gene-specific selection system. f Adoption of GSR varieties in various ecosystems 


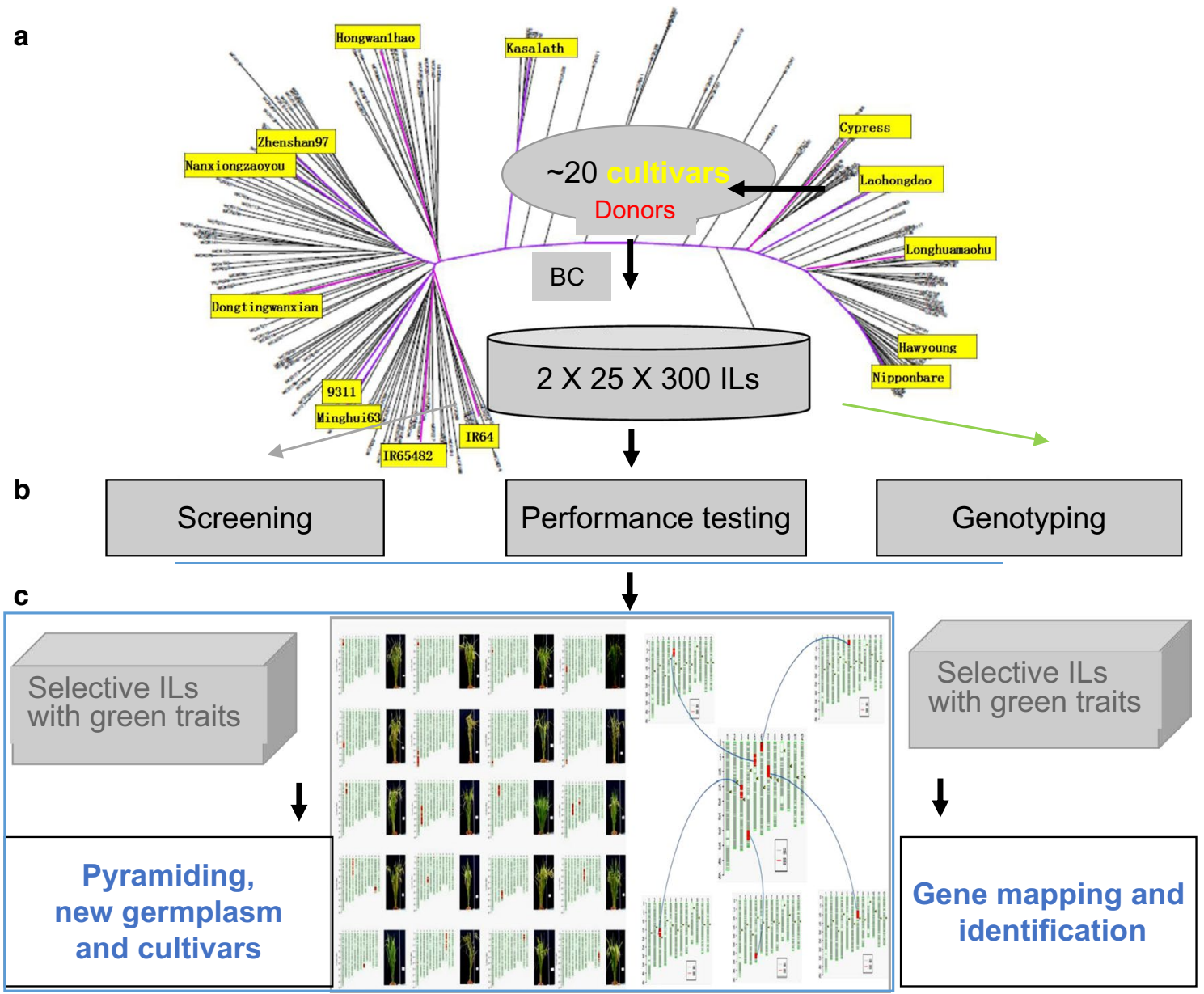

Fig. 2 Massive backcrossing strategy for the development of GSR varieties: a Large-scale cross of diverse donors with elite parents and massive repeated backcrossing (BC) to one elite parent to generate near-isogenic lines or introgression lines (IL) with the desirable genes

system of rice varieties was built by taking advantage of high-throughput SNP chips. The system was used for genotypic identification of the pedigree and derivative pedigree materials of a superior rice variety, Huanghuazhan (HHZ) for GSR development. As a result, a total of 1113 conserved and traceable chromosomal regions were identified, including genes related to many important agronomic traits, such as $s d l$ (controlling plant height), Ehd4 (controlling heading date), htdl (controlling tiller height and dwarfing), SSIIa (controlling soluble starch synthesis), GS3 (controlling grain size), Amy $3 A$ (controlling amylase), Gnla (controlling grain number), and TACl (controlling tillering angle) (Zhou et al. 2016a; Chen et al. 2017).

The sequence analysis of a large number of varieties resulted in the identification of the selected genomic regions during breeding and characterized two subpopulations ( $I$ and II) for the Xian (indica) subspecies, which have distinct geographic origins, resulting from separate breeding activities or traits. b Genotyping and phenotyping of the selective IL population to identify genetic variations for the target traits. c Elite lines carrying a single gene of interest may be combined to develop GSR cultivars

of China and the International Rice Research Institute during the early "Green Revolution." In addition, about 200 genomic regions subjected to different selections among different Xian subpopulations were found (Xie et al. 2015). These regions cover some genes with known functions and related to green traits as well as many loci with unknown functions. These selected loci will provide important targets for the further improvement of rice.

Many cloned genes with disease resistance have been widely applied to the breeding and improvement of new GSR varieties (Jiang et al. 2016; Hu et al. 2016, 2017). These included introduction of $\mathrm{Pi2}$ (blast resistance gene) and $\mathrm{Xa23}$ (bacterial blight resistance gene) into the photo-thermo-sensitive genic male sterile (PTGMS) line Guangzhan63-4S, which significantly enhanced the resistance of newly developed two-line hybrid breeding lines to bacterial blight and blast (Jiang et al. 2015a). In addition, two genes, Bphl4 and Bph15 conferring resistance to 
brown planthoppers were together introduced into a superior restorer line, Huahui 93. The resultant NILs carrying Bph14 and Bph15 showed much improved resistance to brown planthoppers (Wang et al. 2016). Through markerassisted backcross breeding, new 9311 lines carrying different combinations of brown planthopper resistance genes/loci (QBph3, QBph4, Bph6, Bph3, Bph9, Bph10, Bph14, Bph15, $B p h 17, B p h 18, B p h 20, B p h 21$, and Bph24) were developed, which showed stronger brown planthopper resistance at the seedling stage (Xiao et al. 2016). Recently, a novel gene, $B p h 38(t)$ on the long arm of chromosome 1, was mapped to a small genomic region of $496.2 \mathrm{~kb}$ explaining the phenotypic variation of $35.9 \%$ in a backcross population derived from a cross of HHZ and Khazar (Balachiranjeevi et al. 2019).

Breeding of new GSR varieties with high nitrogen-use efficiency is a critical way to reduce the application of nitrogenous fertilizer in rice production and is one of the primary goals of our GSR breeding as well. Jewel et al. (2019a) reported a unique and systematic breeding approach through the selection of introgression lines with higher nutrient-use efficiency (NUE) through the early backcross breeding program. The selection of ILs was carried out for four consecutive seasons under different combinations of $\mathrm{N}, \mathrm{P}$, and $\mathrm{K}$ dosages of fertilizer. Five promising ILs (Nue-115, Nue114, Nue-112, Nue-229, and Nue-230) were identified as having high grain yield and significantly improved NUE. These ILs provided valuable materials and information in rice breeding programs for high NUE. Quantitative trait loci (QTLs) related to NUE were identified earlier by several researchers (Liu et al. 2016; Zhou et al. 2017a, b; Feng et al. 2018). Recently, Jewel et al. (2019b) detected a total of 49 main-effect QTLs in six nutrient conditions. These QTLs explained phenotypic variation ranging from 20.3 to $34.7 \%$ and were located on all 12 chromosomes, except on chromosomes 7, 11, and 12. Among these QTLs, four hotspot QTLs were identified on chromosomes 3, 5, 9, and 11. Interestingly, novel QTLs for partial factor productivity (22 QTLs) and agronomic efficiency (four QTLs) were detected for -P and $75 \%$ of recommended $N$ conditions. Several candidate genes were identified in these QTLs regions, and they were involved in nutrient uptake and transporting mechanisms. Mahender et al. (2019) identified a total of 19 QTLs associated with three favorable agronomic traits by using tunable genotyping-by-sequencing technology. Interestingly, two QTLs ( $q L C-I I \_1$ and $\left.q L C-I I \_11\right)$ were detected for chlorophyll content under zero percentage of $\mathrm{N}, \mathrm{P}$, and $\mathrm{K}$ fertilizer. Together, these QTL regions and candidate genes would be of great value for marker-assisted selection and pyramiding of multiple QTLs for improving NUE in rice.

Several genes related to high nitrogen-use efficiency have been cloned. These included OSNRT1 (Lin et al. 2000), OsDUR3 (Wang et al. 2012a), OsPTR6 (Fan et al. 2014), $q N G R 9 / D E P 1$ (Sun et al. 2014), NRT1.1B (Hu et al. 2015a),
OsNRT2.3 (Fan et al. 2016), and GRF4 (Li et al. 2018a). Among them, NRT1.1B appears to be the most promising one. The primary function of this gene is its transport activity of nitrate and is strongly induced by nitrate ( $\mathrm{Hu}$ et al. 2015a; Zhang et al. 2019). This gene shows apparent differentiation between Xian and Geng (japonica), and NRT1.1B (the Xian allele) had undergone through strong artificial selection during domestication. The allelic variation of $N R T 1.1 B$ was found to be responsible for the big difference in nitrogen-use efficiency between Xian and Geng. Thus, $N R T 1.1 B$-Xian has great application value in GSR breeding and production. The introduction of NRT1.1B-Xian into Xiushui 34, a late-maturing Geng variety in Zhejiang, China, resulted in the development of several new high-yielding lines with greatly improved NUE. Of these new lines, the best one yielded $10.2 \mathrm{tha}^{-1}$ under a moderate rate of nitrogen input (a reduction in nitrogen fertilizer per hectare from 180 to $100 \mathrm{~kg}$ in Hubei, China), exhibiting great potential for high nitrogen-use efficiency.

Abiotic stresses are the most important factors limiting rice productivity in many rice ecosystems. Among the various abiotic stresses, drought severely affects rice production and causes substantial yield losses in drought prone areas of rice (Hu and Xiong 2014). Thus, identification of loci for stress resistance and the development of GSR varieties with improved resistance to a single or multiple stresses are of great significance in solving the proble. In rice, several genes related to abiotic stress resistance have been cloned (Table 1). These included some loci or candidate genes associated with drought tolerance (Ren et al. 2005; Redillas et al. 2012; Uga et al. 2013; Zhu and Xiong 2013; Huang et al. 2014; Zhang et al. 2016). Several other genes are also of value for improving rice resistance to abiotic stresses. These included three cloned genes (COLD1, bZIP73, and HANI) for cold tolerance at seedling stage (Ma et al. 2015; Liu et al. 2018b; Mao et al. 2019), CTB4a for cold tolerance at the booting stage (Zhang et al. 2017a) and TTl for high-temperature resistance ( $\mathrm{Li}$ et al. 2015). Although many genes for stress resistance have been cloned, the most successful application of these cloned stress tolerance genes in rice breeding was $S U B 1$ for submergence tolerance. This gene has been successfully introgressed into several mega rice varieties which showed significantly improved yields under natural flooding (Ismail et al. 2013).

Besides the advantages of resistance to various diseases, insects, and stresses and high nitrogen-use efficiency, the newly developed GSR varieties are characterized by high quality and yield. Currently, several genes related to yield and grain quality have been cloned in rice (Xing and Zhang 2010; Wang et al. 2012b, 2015a). The elite allele of IPAI (ipal-2D) for an ideotype is located in a tandem repeat sequence upstream of the IPAI gene, and variation in the gene structure would lead to a decrease in the methylation 
Table 1 Representative genes related to green traits from 2014 to 2019

\begin{tabular}{|c|c|c|c|c|c|}
\hline Green trait & Gene & Accession number & Chr. & Function causes & References \\
\hline \multirow[t]{10}{*}{ Grain yield/grain quality } & OsAAP6 & LOC_Os01g65670 & 1 & $\begin{array}{l}\text { Expression change by variations } \\
\text { in promoter }\end{array}$ & Peng et al. 2014 \\
\hline & GL2/GS2/OsGRF4 & LOC_Os02g47280 & 2 & Expression change & $\begin{array}{l}\text { Che et al. (2015), Duan } \\
\text { et al. (2015) and Hu } \\
\text { et al. (2015b) }\end{array}$ \\
\hline & GNP1 & LOC_Os03g63970 & 3 & $\begin{array}{l}\text { Expression change by variations } \\
\text { in promoter }\end{array}$ & Wu et al. (2016) \\
\hline & $\lg 33$ & LOC_Os03g11614 & 3 & Protein structure & Liu et al. (2018a) \\
\hline & GL3.3/TGW3/qTGW3 & LOC_Os03g62500 & 3 & Premature termination & $\begin{array}{l}\text { Hu et al. (2018), Xia et al. } \\
\text { (2018) and Ying et al. } \\
\text { (2018) }\end{array}$ \\
\hline & Chalk5 & LOC_Os05g06480 & 5 & $\begin{array}{l}\text { Expression change by variations } \\
\text { in promoter }\end{array}$ & Li et al. (2014) \\
\hline & $G W 5$ & LOC_Os05g09520 & 5 & $\begin{array}{l}\text { Expression change by variations } \\
\text { in promoter }\end{array}$ & Liu et al. (2017) \\
\hline & $G W 7 / G L 7$ & LOC_Os07g41200 & 7 & $\begin{array}{l}\text { Expression change by variations } \\
\text { in promoter }\end{array}$ & Wang et al. (2015a, c) \\
\hline & GLW7/OsSPL13 & LOC_Os07g32170 & 7 & $\begin{array}{l}\text { Expression change by variations } \\
\text { in promoter }\end{array}$ & Si et al. (2016) \\
\hline & OsOTUB1 & LOC_Os08g42540 & 8 & $\begin{array}{l}\text { Expression change by variations } \\
\text { in promoter }\end{array}$ & Wang et al. (2017b) \\
\hline \multirow[t]{10}{*}{ Disease/insect pest resistance } & $B s r-d l$ & LOC_Os03g32230 & 3 & $\begin{array}{l}\text { Expression change by variations } \\
\text { in promoter }\end{array}$ & Li et al. (2017) \\
\hline & Bph3 & LOC_Os04g12540 & 4 & Amino acid substitution & Liu et al. (2015) \\
\hline & & Os04g0202350 & 4 & Premature termination & \\
\hline & & LOC_Os04g12580 & 4 & Amino acid substitution & \\
\hline & ВРН6 & LOC_Os04g35210 & 4 & $\begin{array}{l}\text { Amino acid substitution and } \\
\text { deletion }\end{array}$ & Guo et al. (2018) \\
\hline & PigmR & LOC_Os06g17900 & 6 & Amino acid substitution & Deng et al. (2017) \\
\hline & IPAl & LOC_Os08g39890 & 8 & $\begin{array}{l}\text { Expression change by variations } \\
\text { in promoter }\end{array}$ & Wang et al. (2018) \\
\hline & STV11 & LOC_Os11g30910 & 11 & $\begin{array}{l}\text { Amino acid substitution and } \\
\text { deletion }\end{array}$ & Wang et al. (2014) \\
\hline & Xalo & LOC_Os11g37620 & 11 & Gene deletion & Tian et al. (2014) \\
\hline & ВPH9 & LOC_Os12g37280 & 12 & $\begin{array}{l}\text { Amino acid substitution and } \\
\text { deletion }\end{array}$ & Zhao et al. (2016) \\
\hline \multirow[t]{3}{*}{ Nutrient-use efficiency } & $D E P 1$ & LOC_Os09g26999 & 9 & Amino acid substitution & Sun et al. (2014) \\
\hline & NRT1.1B & LOC_Os10g40600 & 10 & Amino acid substitution & Hu et al. (2015a) \\
\hline & GRF4 & LOC_Os02g47280 & 2 & Expression change & Li et al. (2018a) \\
\hline \multirow[t]{5}{*}{ Cold resistance } & $L G S 1$ & LOC_Os02g47280 & 2 & Expression change & Chen et al. (2019a, 2019b) \\
\hline & COLD1 & LOC_Os04g51180 & 4 & Amino acid substitution & Ma et al. (2015) \\
\hline & CTB $4 a$ & LOC_Os04g04330 & 4 & $\begin{array}{l}\text { Expression change by variations } \\
\text { in promoter }\end{array}$ & Zhang et al. (2017a) \\
\hline & $b Z I P 73$ & LOC_Os09g29820 & 9 & Amino acid substitution & Liu et al. (2018b) \\
\hline & HAN1 & LOC_Os11g29290 & 11 & $\begin{array}{l}\text { Expression change by variations } \\
\text { in promoter }\end{array}$ & Mao et al. (2019) \\
\hline Heat resistance & OsTT1 & LOC_Os03g26970 & 3 & Amino acid substitution & Li et al. (2015) \\
\hline
\end{tabular}

level in the promoter region of IPAl, resulting in increased expression of IPAI, which contributes to an ideotype and appropriate tiller number to promote yield (Wang and Wang 2017; Zhang et al. 2017b; Wang et al. 2018b). In addition, a gene that influences spikelet number can increase the number of rice grains to elevate yield by more than $5 \%$ (Wu et al. 2016). The grain quality of rice mainly comprises processing, appearance, and nutritional and cooking qualities, which directly or indirectly determine the value of rice. At present, several genes related to rice quality have been 
cloned (Sano et al. 1986; Gao et al. 2003; Bradbury et al. 2005). For example, Chalk5 loosens the structure and affects the content of starch granules, causing chalkiness of rice grains (Li et al. 2014). Two other genes, ssIIIa and $w x$, can synergistically regulate rice grain quality, and molecular markers linked to these two genes have been designed for their application in breeding (Zhou et al. 2016b).

\section{Establishment of genome databases for rice breeding}

During the implementation of the GSR project, several databases for rice genomic variations were established. These databases provide key platforms for gene functional research and whole-genome selection breeding for rice. For example, a core collection of 3024 rice accessions representing nearly $95 \%$ of the total genetic diversity of 780 thousand rice germplasm collection maintained in gene banks worldwide were re-sequenced and analyzed. As a result, a total of 42 million single nucleotide polymorphisms (SNPs) and more than 100 thousand structural variations (deletion, translocation, inversion, and duplications) were identified, and $\sim 20$ thousand new genes were discovered. The $3 \mathrm{~K}$ Rice Genome Project established the pan-genome of the Asian cultivated rice and revealed its population structure (Wang et al. 2018a). Based on the information on rice genomic variations, a new multifunctional and comprehensive rice functional genomics and breeding database (RFGB) has been established, which included a rice sequence polymorphism information retrieval system, an explorer visualization system of the genome, and data output system for specific genome regions (http://www. rmbreeding.cn/) (Sun et al. 2016).

Currently, the GSR project integrated the re-sequencing data of more than 6000 rice genomes worldwide, carried out haplotype analysis on the whole-genome structural variations, and investigated the selected genomic regions during the breeding process. As a result, a database of rice SNPs (http://variation.ic4r.org/) was created. A platform for the marker-assisted molecular breeding of GSR was established (http://47.92.174.110), which can help to compare genotypes and predict the performances of breeding materials. In addition, the database of rice genomic variations RiceVarMap v2.0 (http://ricevarmap.ncpgr.cn/v2/) was improved, integrating all data on genomic variations, annotation of the functional variations, phenotypes, and genome-wide association studies (Zhao et al. 2015). These databases provide abundant information resources for molecular design breeding to develop new GSR varieties with high yield, high quality, and general adaptability and could help to enhance the efficiency of GSR breeding (Fig. 1) and promote the transition from the conventional "experience-based breeding" to the highly accurate and efficiently designed breeding.

\section{Software for genomic selection breeding}

Genomic selection (GS) refers to the establishment of a correlation between marker genotypes and phenotypes for predicting performances of breeding populations for unknown phenotypes based on the markers and phenotypes of related (smaller) reference populations. One of the advantages of GS is its higher efficiency relative to the traditional phenotypic selection methods practiced in the conventional breeding, as it requires phenotyping fewer hybrids, and is capable of predicting the phenotypes of hybrids that have not undergone field tests based on genotypic data (Xu et al. 2014; Spindel et al. 2016; Yang et al. 2017). The GSR project developed a GS software gblup.jar based on the new genomic best linear unbiased prediction (GBLUP-AD) that includes both the additive and dominance effects. This software can be used to predict the performances of multiple traits and environmental effect. The GBLUP-AD has been used to predict the phenotypes of rice hybrids based on NCII design, and the predictive ability was significantly improved (Wang et al. 2017a). Also, the project has designed the gblupdesign. jar software based on Java which is able to predict the founder parents with the highest breeding values and the ideal genotypes to be used for molecular design breeding.

\section{The platform of genomic selection breeding of rice}

The platform of genomic selection breeding established based on the research findings of genomics, breeding chips, and high-throughput sequencing provided solid technical support for the genomics-assisted breeding strategies and rapid development of new GSR varieties (Fig. 1). This GS technology can be applied to commercial breeding to accelerate the progress of commercialization of breeding and promote the transition from the conventional breeding to more accurate and efficient genomic breeding.

The GSR project has also developed three highthroughput breeding chips of rice based on Illumina's Infinium technology, which constitute a GS technical system in our GSR breeding efforts. The three breeding chips include a RICE6K chip (Yu et al. 2014), a RICE60K chip (Chen et al. 2014), and a RICE90K chip, which comprise $4473,43,386$, and 85,000 high-quality markers, respectively. Based on the Hiseq $4000, \times$ Ten, and BGISEQ-500 sequencing platforms, a high-throughput and low-cost whole-genome selection breeding platform that is not restricted by any specific reference genomes 
was set up. This platform can be used for the construction of genetic linkage maps, genetic diversity analysis, variety identification, and gene/QTL mapping. Currently, the platform has been widely applied to the analysis of genetic diversity of rice germplasm, genome-wide association studies, and molecular breeding activities (Yu et al. 2016; Qiu et al. 2018; Zhang et al. 2018). For example, the whole-genome breeding technology has been applied toward the improvement of biotic resistance of elite rice cultivars that have been widely grown as founder parents. The perfect introduction of resistance genes for rice blast and brown planthopper significantly enhanced the disease/ insect resistance of the parents without altering the overall agronomic traits. The introduction of multiple blast resistance genes into a single parent or variety has contributed to the generation of NILs with a highly consistent genetic background (Wing et al. 2018; Zhang et al. 2018). The combination of various NILs with different blast resistance genes resulted in the development of varieties with consistent agronomic traits and high and stable resistance. In addition, the $S 5$-n and/or $f 5-n$ from the wide compatibility variety Dular were introduced into the restorer line 9311, and the rapid detection of its background with RICE6K revealed a background recovery rate as high as $99.4 \%$, resulting in the generation of improved 9311 with wide compatibility (Mi et al. 2016).

\section{Development of new pre-breeding GSR lines with pyramided green genes}

Based on the information on cloned green genes and loci, large-scale cross and backcross breeding was conducted to generate IL populations and lines abundant in green traits with wild rice, core germplasm, and specific local varieties as the donors (Fig. 2). As a result, a large number of restorer lines, male sterile lines, and new pre-breeding lines with the advantages of disease/insect resistance, weed-competitive ability, high nitrogen- and phosphorususe efficiency, water-saving, drought tolerance, and high yield and quality were bred (Jiang et al. 2015b, 2016; Xiao et al. 2016; Wang et al. 2016; Dimaano et al. 2017). Meanwhile, these lines were screened and identified for their resistance to drought, low phosphorus, low nitrogen, weed-competitive ability, blast, bacterial blight, rice false smut, and rice planthopper, creating a batch of new germplasm with multiple green traits such as multi-resistance, high nutrient-use efficiency, water-saving, drought tolerance, and high yield and quality. For example, the superior indica varieties HHZ and restorer line 9311, which are widely planted in central and southern China and later identified as highly adaptable to Asian and African target locations, were used as the recipients to breed a series of disease-/insect-resistant NILs with multiple brown planthopper resistance genes (such as Bphl, Bph14, and $\mathrm{Bph15}$ ) and disease resistance genes (such as $\mathrm{Pi2}, \mathrm{Pi}$, and $P i k m$ ). The dominant genic male sterile line JiafuzhanS was used as a facilitator for outcrossing to generate new lines with several disease resistance genes (such as Pi1, Pi2, Xa21, and Xa23). Also, two-line hybrid lines Y58S, Hua1017S, and Hua1037S harboring various disease/insect resistance genes (such as Pi2, Pi9, Pikm, Bph3, $B p h 14, B p h 32, X a 7, X a 21$, and $X a 23$ ) and elite genes of aroma were generated, and exhibited excellent application potential. These research findings will provide abundant necessary materials for the use of important agronomic traits and crop improvement, and are of guiding significance to the molecular design breeding of NILs with the target traits.

Globally, more than USD 100 billion are spent annually for weed control of the crops (Appleby et al. 2001). Therefore, breeding of weed-competitive (WC) rice varieties is a critical solution to reduce tillage operations and decrease hand weeding and herbicide inputs in the direct-seeded rice system. In this regard, the drought pyramiding GSR variety IR83140-B-11-B performed well in partial weed control plots, yielding 2850 and $4610 \mathrm{~kg} \mathrm{ha}^{-1}$ in the wet and dry seasons at the International Rice Research Institute (IRRI), respectively (Chauhan et al. 2015). At an early stage of the crop, the trials showed that grain yield in different GSR genotypes was positively correlated with leaf area. We initiated the systematic breeding of rice varieties with weed-competitive ability by standardizing the phenotypic screening protocol to identify the weed-competitive traits related to early seed germination, early seedling vigor, and weed-competitive components. The breeding materials were developed from four early-generation backcross populations derived from one common recipient parent, WTR-1, and four different donors, Y134, Zhong 143, Khazar, and Cheng Hui-448. These ILs were evaluated in three rounds of selection in upland weed-free, upland-weedy, and lowland-weedy conditions. Five ILs (G-6-L2-WL-3, G-6-RF6-WL-3, G-6-L15WU-1, G-6-Y16-WL-2, and G-6-L6-WU-3) were found to be promising ILs in lowland-weedy conditions, whereas four ILs (G-6-Y7-WL-3, G-6-Y6-WU-3, G-6-Y3-WL-3, and G-6-Y8-WU-1) were found to have the highest grain yield under upland-weedy conditions (Dimaano et al. 2017). For the molecular genetics of weed-competitive rice cultivars, a total of 44 QTLs were mapped on 12 chromosomes, except on chromosomes 4 and 8 , by using 677 high-quality SNP markers. Interestingly, 29 novel genetic loci were associated with early seed germination and early seedling vigor traits on chromosomes $1,3,5,6,7,10,11$, and 12 . The hotspot regions of chromosomes 11 and 12 were associated with multiple traits (Dimaano et al. 2019, unpublished). Many of these QTLs were co-localized with previous reported QTLs, 
which were related to germination rate, germination index, germination percentage, and germination time in different genetic backgrounds of mapping populations (Mahender et al. 2015).

\section{Demonstration and application of GSR varieties in China}

Based on the latest findings in genomics and bioinformatics research, oriented transfer and pyramiding of the favorable genes associated with rice yield, quality, disease/insect resistance, drought tolerance, and nutrient-use efficiency were carried out by using different techniques such as pedigree breeding, backcross breeding, combining ability breeding, marker-assisted selection, and whole-genome selection breeding (Fig. 1), resulting in the generation of new materials with multiple elite genes and GSR varieties with various desirable traits.

As of the end of 2018, a total of 66 new varieties developed by the GSR project had been registered in China (Table S1). The cumulative planting area of these cultivars over five main rice-growing regions exceeded 6.67 million hectares from 2014 to 2018 , laying a solid foundation for promoting the sustainable development of rice production. For instance, in a two-year experiment on nitrogen fertilizer reduction, the partial factor productivity of applied $\mathrm{N}$ of hybrid variety Huiliangyou 630 increased by $10.2 \%$ compared with that of the control; in addition, this variety is characterized by high quality and resistance to blast and bacterial blight. Overall, it has reached the standards of a GSR variety $(10 \%$ increases in the use efficiency of nitrogen fertilizer, phosphorus fertilizer, and water, respectively, and with moderate resistance to one or more main diseases or insects). The cumulative planting area of Huiliangyou 630 reached 210 thousand hectares during 2015-2018. Under the reduction of $30 \%$ in nitrogen fertilizer, the partial factor productivity of applied $\mathrm{N}$ of Jingliangyouhuazhan in two years increased by $23.2 \%$ relative to that of the control. This variety also has the characteristics of disease resistance, high nitrogen-use efficiency, low cadmium accumulation, high yield and quality, and wide adaptability. The cumulative planting area of Jingliangyouhuazhan reached 530 thousand hectares during 2016-2018, increasing rice yield by 320 thousand tons and decreasing the input of pesticide and fertilizer by 160 million yuan (about USD 22.86 million). Owing to its high grain quality and multiple resistances, the variety Wushansimiao has been planted on a cumulative area of 730 thousand hectares in southern China. One new variety, Wushansizhan, which was derived from Wushansimiao, is characterized by the advantages of high resistance to blast; moderate resistance to bacterial blight, lodging, and cold; and high grain quality.

\section{International popularization and application of GSR varieties}

The demonstration and popularization of new GSR varieties have strongly promoted the development of superior rice production in the target regions. GSR materials were systematically introduced to 16 African and Asian countries with IRRI and AfricaRice for helping in the adaptation testing, breeding, and capacity building of local national agricultural research and extension system (NARES) partners. The GSR project involved 32 Chinese institutions, universities, academies, and seed companies partnering in the massive development and deployment of GSR products (Fig. 3). This led to the release of 59 GSR varieties that were adapted to the rice production areas of Africa and Asia (Table S2). Other 97 GSR cultivars were identified as promising and entered into national cooperative yield trials for their release in different target countries (Table S3). Among the 59 GSR varieties, HHZ was released in Mozambique, Indonesia, and India, demonstrating its wide-adaptation features. Further, HHZ provided an excellent base recipient parent for introgression breeding that led to the identification and release of 15 varieties with multiple stress tolerance (with GSR IR1 prefix) across different target countries in Asia and Africa. Interestingly, GSR variety $\mathrm{HHZ}$ was released in Punjab State in India as PR126 in 2017, which was of short duration (123 days) and yielded on a par with a dominant longduration variety (Pusa 44), fitting well in the rice-potato cropping system. The average productivity per day over a hectare of PR126 was $61 \mathrm{~kg}$ vis-à-vis $46.9 \mathrm{~kg}$ of Pusa 44 . Due to the earliness of PR126, Punjab saved on irrigation water and fertilizer while keeping the same yield levels of Pusa 44. PR126 is fast replacing predominant variety Pusa 44, especially in the rice-potato cropping belt, with a current adoption area of $31.6 \%$ (Veettil et al. 2019). This variety alone has created enormous socioeconomic and environmental impacts and is currently being studied. We have now created several hundred introgression lines with multiple abiotic stress tolerance in an HHZ background derived from different donors that outperform the recipient parent in grain yield and maturity. Soon, these lines may replace $\mathrm{HHZ}$ to create more significant socioeconomic impacts. Among them, 74 promising derivatives (with GSR IR1 prefix) in an HHZ background are being evaluated in national cooperative trials in India, Bangladesh, Pakistan, Indonesia, the Philippines, Mozambique, and Uganda (Table S3). 
32 Chinese institutions/companies + 26 NARES and partners

\begin{tabular}{l} 
CHINA \\
\hline Chinese Academy of Agricultural Sciences (CAAS) \\
Huazhong Agricultural University (HAU) \\
Shanghai Agrobiological Gene Center (SAGC) \\
Chinese Academy of Sciences (CAS) \\
Peking University (PU) \\
Sichuan Academy of Agricultural Sciences (SAAS) \\
Guangdong Academy of Agricultural Sciences (GDAAS) \\
Guangxi Academy of Agricultural Sciences (GXAAS) \\
Helongjiang Academy of Agricultural Sciences (HLJAAS) \\
Yunnan Academy of Agricultural Sciences (YAAS) \\
Anhui Academy of Agricultural Sciences (AAAS) \\
Jiangxi Academy of Agricultural Sciences (JAAS) \\
China National Rice Research Institute (CNRRI) \\
Fujian Academy of Agricultural Sciences (FAAS) \\
Guizhou Academy of Agricultural Sciences (GZAAS) \\
Ningxia Academy of Agricultural Sciences (NAAS) \\
Hunan National Hybrid Rice Center (HNHR) \\
Nanjin Agricultural University (NAU)
\end{tabular}

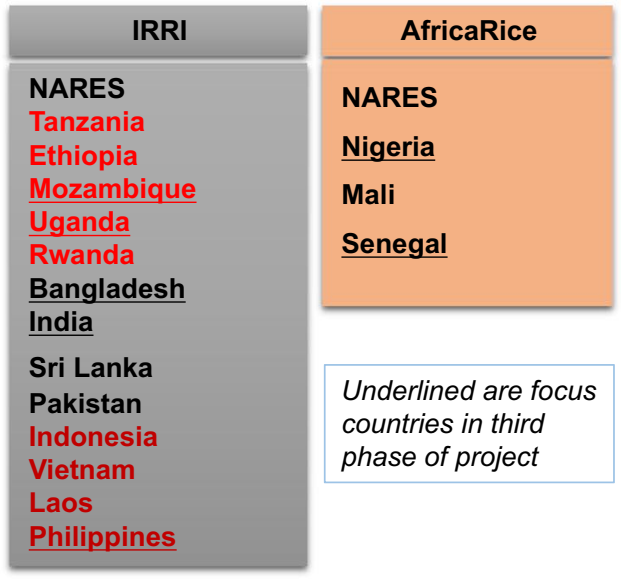

Chinese seed companies (7)

Chinese-built-agricultural demonstration centers in African countries (2)

Fig. 3 The GSR project participants in China, Asia, and Africa in collaboration with IRRI and AfricaRice

An excellent socioeconomic performance has been achieved by the popularization of GSR varieties in the target African and Asian countries. Socioeconomic assessment of some GSR varieties bred for rainfed and irrigated lowland environments in the Philippines and Bangladesh showed that GSR varieties contribute significantly to the yield and net income of farmers (Ali et al. 2012; Yorobe et al. 2016). Compared with conventional rice, GSR varieties showed significantly enhanced yield and economic output (by 0.89-1.83 tons and USD 230.90 per hectare, respectively) and disease/insect resistance (Yorobe et al. 2016). Currently, 59 varieties have passed regional tests and variety approval in countries in South Asia (Bangladesh, India, Pakistan, and Sri Lanka), Southeast Asia (Indonesia, Laos, Cambodia, the Philippines, and Vietnam), and Africa (Mozambique, Uganda, Rwanda, Nigeria, Senegal, and Mali) (Table S3). The cumulative area of the demonstration and popularization of GSR varieties in African, South Asian, and Southeast Asian countries has reached about 2.34 million hectares, which marked significant contributions to rice production and food security in these countries (Wang et al. 2018c).

\section{Identification criteria of GSR varieties and highly efficient cultivation systems}

The breeding of superior varieties is a genetic approach, while improved cultivation techniques are non-genetic approaches to achieve higher grain yield and higher efficiency. The GSR project has established a complete assessment system for evaluating the green traits of GSR varieties and clarifying the related mechanisms. The establishment of a cultivation and field management system for GSR and a comprehensive prevention and control system for the primary diseases and insects provides essential support for the promotion of resource-use efficiency based on higher grain yield and stability, and for 
the environment-friendly and sustainable development of rice production.

The GSR project also successfully developed a series of key cultivation techniques for GSR varieties, such as site-specific nutrient management, precise water-saving irrigation technology, straw incorporation, and direct seeding (Wang and Peng 2017; Zhou et al. 2017a, b). During 2014-2018, the cumulative application area of GSR cultivation reached 3.48 million hectares (Zhang et al. 2018), thereby reducing the cost of fertilizer, pesticide, and water by 12.34 billion yuan (about USD 1.76 billion) in China alone.

The component "High-Yielding and Efficient Cultivation Technology of Ratooned Rice with Main Crop Harvested Mechanically" of the GSR project integrates ratoon rice varieties of high quality and yield and a series of key cultivation techniques. This project has implemented the demonstration and application of ratooned rice in large areas of Hubei Province, China, with a demonstration area of nearly 270 thousand hectares. In Hunan Province, a highefficiency and high-yield cultivation technical system has been assembled, which is characterized by resistance to cold, high temperature, lodging, and banded sclerotial blight, and enhanced seedling regeneration ability. During 2014-2018, the cumulative application area of GSR cultivation was 110 thousand hectares. In Guangdong Province, the demonstration and application of "water- and fertilizer-saving" cultivation were conducted. During 2014-2016, the cumulative application area of this cultivation technique in this province reached 2.67 million hectares, reducing the cost of fertilizer and pesticide by 1.97 billion yuan (about USD 28 million), and increasing rice grain yield by 1.84 million tons and income by 7.31 billion yuan (about USD 1.04 billion).

\section{Prospects of GSR development}

The world population is expected to reach nine billion in 2050. The rapid increase in population demands corresponding increases in rice production in a sustainable way, which will be a great challenge to global rice breeders in future decades. GSR is therefore a vital concept proposed to meet this challenge since GSR varieties can maintain stable and higher yield with less inputs, and have stronger resistance and recoverability features when facing the frequent occurrence of extreme stresses caused by climate changes. The practice in the past decade has demonstrated that the combination of GSR varieties and corresponding improved cultivation techniques can contribute to more stable and higher yields, and at the same time reduce the application of pesticide and fertilizer by more than $30 \%$, as well as irrigation water by at least $30 \%$ in irrigated rice production areas. GSR may become a vital pattern to lead the green development of agriculture, and its goals and whole-genome breeding strategies may provide patterns or set examples for the development of other crops. The implementation of the GSR project has led to and promoted the transition of breeding goals and production modes of crops in China, and across the world (Wing et al. 2018).

The strategies to breed GSR varieties using multipleomics not only greatly promote breeding accuracy and efficiency but also accelerate the commercialization and all-around transition and upgrading of crop breeding. By combining the abundant germplasm accessions, functional genomics, and molecular breeding with whole-genome selection, a large number of new varieties and accessions were used in the pyramiding of elite genes in pedigree breeding and backcross breeding. These varieties and accessions harbor various elite genes associated with high yield, superior grain quality, disease/insect resistance, drought tolerance, and higher nutrient efficiency. Genome-editing technology is becoming a key technology for genomic breeding owing to its advantages of high efficiency, low cost, and safety. For example, CRISPR/Cas technology provides efficient and versatile tools for efficient targeted modification of the genes of agricultural importance in crops and precision crop breeding (Chen et al. 2019a). Compared with conventional breeding, it greatly promotes the efficiency of pyramiding elite genes, and can create more abundant genetic resources with high yield, superior grain quality, and tolerance to various stresses.

During the demonstration and popularization of GSR varieties, technical training programs have conveyed the green concept and cultivation techniques of high quality, high yield, and efficiency to farmers, which significantly improves the technical quality of the workers or farmers in these areas. Also, the integration and innovation of green varieties and cultivation techniques have optimized rice production techniques, enhanced per unit area yield, and increased the income of farmers. An international network for cooperation involving the IRRI and AfricaRice, along with NARES partners in Africa and Asia, was established. In the short term, more and better GSR varieties with high adaptability to climate changes should be bred, alongside the development of corresponding green yield- and efficiencypromoting cultivation techniques. These goals require active cooperation among various fields of breeding, agronomy, agricultural machinery, and agricultural economics, with the sole purpose of increasing the income of small farm households in the target countries, ensuring food security, and promoting the sustainable development of global agriculture.

Acknowledgements This research was supported by grants from National High Technology Research and Development of China 
(2014AA10A600) and the Bill and Melinda Gates Foundation (OPP1130530).

Author contributions QZ had the idea for the review. CZ performed the literature collection. SY and JA drafted the manuscript. QZ and ZL revised the manuscript.

\section{Compliance with ethical standards}

Conflict of interest The authors declare that they have no conflict of interest.

Open Access This article is licensed under a Creative Commons Attribution 4.0 International License, which permits use, sharing, adaptation, distribution and reproduction in any medium or format, as long as you give appropriate credit to the original author(s) and the source, provide a link to the Creative Commons licence, and indicate if changes were made. The images or other third party material in this article are included in the article's Creative Commons licence, unless indicated otherwise in a credit line to the material. If material is not included in the article's Creative Commons licence and your intended use is not permitted by statutory regulation or exceeds the permitted use, you will need to obtain permission directly from the copyright holder. To view a copy of this licence, visit http://creativecommons.org/licenses/by/4.0/.

\section{References}

Ali J, Xu JL, Gao YM, Fontanillo MA (2012) Innovative Green Super Rice (GSR) molecular breeding strategy: achievements and advances. Philipp J Crop Sci 37:49

Ali J, Jewel ZA, Mahender A, Anandan A, Hernandez J, Li ZK (2018) Molecular genetics and breeding for nutrient use efficiency in rice. Int J Mol Sci 19:1762

Appleby AP, Müller F, Carpy S (2001) Weed control. Ullmann's Encyclopedia of Industrial Chemistry. Wiley-VCH Verlag GmbH \& Co. KGaA, New York

Balachiranjeevi CH, Prahalada GD, Mahender A, Jamaloddin Md, Sevilla MAL, Marfori-Nazarea CM, Vinarao R et al (2019) Identification of a novel locus, $B P H 38(\mathrm{t})$, conferring resistance to brown planthopper (Nilaparvata lugens Stal.) using early backcross population in rice (Oryza sativa L.). Euphytica 215:185

Bradbury LMT, Fitzgerald TL, Henry RJ, Jin QS, Waters DLE (2005) The gene for fragrance in rice. Plant Biotechnol J 3:363-370

Chauhan BS, Opeña J, Ali J (2015) Response of 10 elite "Green Super Rice" genotypes to weed infestation in aerobic rice systems. Plant Prod Sci 18:228-233

Che RH, Tong HN, Shi BH, Liu YQ, Fang SR, Liu DP, Xiao YH et al (2015) Control of grain size and rice yield by GL2-mediated brassinosteroid responses. Nat Plants 2:15195

Chen HD, Xie WB, He H, Yu HH, Chen W, Li J, Yu RB et al (2014) A high-density SNP genotyping array for rice biology and molecular breeding. Mol Plant 7:541-553

Chen SX, Lin ZC, Zhou DG, Wang CR, Li H, Yu RB, Deng HC et al (2017) Genome-wide study of an elite rice pedigree reveals a complex history of genetic architecture for breeding improvement. Sci Rep 7:45685

Chen K, Wang Y, Zhang R, Zhang H, Gao C (2019a) CRISPR/Cas genome editing and precision plant breeding in agriculture. Annu Rev Plant Biol 70:667-697

Chen XL, Jiang LR, Zheng JS, Chen FY, Wang TS, Wang ML, Tao Y et al (2019b) A missense mutation in LGS1 increases grain size and enhances cold tolerance in rice. J Exp Bot 70:3851-3866
Deng YW, Zhai K, Xie Z, Yang DY, Zhu XD, Liu JZ, Wang X et al (2017) Epigenetic regulation of antagonistic receptors confers rice blast resistance with yield balance. Science 355:962-965

Dimaano NGB, Ali J, Cruz PCS, Baltazar AM, Diaz MGQ, Acero BL Jr, Li ZK (2017) Performance of newly developed weed-competitive rice cultivars under lowland and upland weedy conditions. Weed Sci 65:798-817

Duan PG, Ni S, Wang JM, Zhang BL, Xu R, Wang YX, Chen HQ et al (2015) Regulation of OsGRF4 by OsmiR396 controls grain size and yield in rice. Nat Plants 2:15203

Elert E (2014) Rice by the numbers: a good grain. Nature 514:50-51

Fan XR, Xie D, Chen JG, Lu HY, Xu YL, Ma C, Xu GH (2014) Overexpression of OSPTR6 in rice increased plant growth at different nitrogen supplies but decreased nitrogen use efficiency at high ammonium supply. Plant Sci 227:1-11

Fan XR, Tang Z, Tan YW, Zhang Y, Luo BB, Yang M, Lian XM et al (2016) Overexpression of a pH-sensitive nitrate transporter in rice increases crop yields. Proc Natl Acad Sci USA 113:7118-7123

FAO (2013) FAOSTAT. http://www.fao.org/faostat/en/

Feng B, Chen K, Cui YR, Wu ZC, Zheng TQ, Zhu YJ, Ali J et al (2018) Genetic dissection and simultaneous improvement of drought and low nitrogen tolerances by designed QTL pyramiding in rice. Front Plant Sci 9:306

Gao ZY, Zeng DL, Cui X, Zhou YH, Yan MX, Huang DN, Li JY et al (2003) Map-based cloning of the $A L K$ gene, which controls the gelatinization temperature of rice. Sci China Ser C: Life Sci 46:661-668

Guo JP, Xu CX, Wu D, Zhao Y, Qiu YF, Wang XX, Ouyang YD et al (2018) Bph6 encodes an exocyst-localized protein and confers broad resistance to planthoppers in rice. Nat Genet 50:297-306

Hazell P, Pomerada C, Valdez A (1986) Crop insurance for agricultural development: issues and experience. J Risk Insur $54: 832-833$

$\mathrm{Hu} \mathrm{HH}$, Xiong LZ (2014) Genetic engineering and breeding of drought-resistant crops. Annu Rev Plant Biol 65:715-741

Hu B, Wang W, Ou SJ, Tang JY, Li H, Che RH, Zhang ZH et al (2015a) Variation in $N R T 1.1 B$ contributes to nitrate-use divergence between rice subspecies. Nat Genet 47:834-838

Hu J, Wang YX, Fang YX, Zeng LJ, Xu J, Yu HP, Shi ZY et al (2015b) A rare allele of $G S 2$ enhances grain size and grain yield in rice. Mol Plant 8:1455-1465

$\mathrm{Hu}$ J, Xiao C, He YQ (2016) Recent progress on the genetics and molecular breeding of brown planthopper resistance in rice. Rice 9:30

Hu KM, Cao JB, Zhang J, Xia F, Ke YG, Zhang HT, Xie WY et al (2017) Improvement of multiple agronomic traits by a disease resistance gene via cell wall reinforcement. Nat Plants 3:17009

Hu ZJ, Lu SJ, Wang MJ, He HH, Sun L, Wang HR, Liu XH et al (2018) A novel QTL $q T G W 3$ encodes the GSK3/SHAGGY-like kinase OsGSK5/OsSK41 that interacts with OsARF4 to negatively regulate grain size and weight in rice. Mol Plant 11:736-749

Huang LY, Zhang F, Zhang F, Wang WS, Zhou YL, Fu BY, Li ZK (2014) Comparative transcriptome sequencing of tolerant rice introgression line and its parents in response to drought stress. BMC Genom 15:1026

Ismail AM, Singh US, Singh S, Dar MH, Mackill DJ (2013) The contribution of submergence-tolerant $(S u b 1)$ rice varieties to food security in flood-prone rainfed lowland areas in Asia. Field Crops Res 152:83-93

Jewel ZA, Ali J, Mahender A, Hernandez J, Pang YL, Li ZK (2019a) Identification of quantitative trait loci associated with nutrient use efficiency traits, using SNP markers in an early backcross population of rice (Oryza sativa $\mathrm{L}$ ). Int J Mol Sci 20:900

Jewel ZA, Ali J, Pang YL, Mahender A, Acero B, Hernandez JE, Xu JL et al (2019b) Developing green super rice varieties with high 
nutrient use efficiency by phenotypic selection under varied nutrient conditions. Crop J 3:368-377

Jiang JF, Mou TM, Yu HH, Zhou FS (2015a) Molecular breeding of thermo-sensitive genic male sterile (TGMS) lines of rice for blast resistance using Pi2 gene. Rice 8:11

Jiang JF, Yang DB, Ali J, Mou TM (2015b) Molecular marker-assisted pyramiding of broad-spectrum disease resistance genes, $P i 2$ and $\mathrm{Xa23}$, into GZ63-4S, an elite thermo-sensitive genic male-sterile line in rice. Mol Breed 35:83

Jiang JF, Mi JM, Ali J, Mu TM (2016) Development of broad-spectrum bacterial blight resistance into thermo-sensitive genic male sterile lines. Plant Breed 135:73-79

Jing RL (2007) Advances of research on drought resistance and water use efficiency in crop plants. Rev China Agric Sci Technol 9:1-5

Khush GS (2001) Green revolution: the way forward. Nat Rev Genet 2:815-822

Li ZK, Ali J (2017) Breeding green super rice (GSR) varieties for sustainable rice cultivation. Burleigh Dodds Science Publishing, Washington. https://doi.org/10.19103/AS.2016.0003.05

Li YB, Fan CC, Xing YZ, Yun P, Luo LJ, Yan B, Peng B et al (2014) Chalk5 encodes a vacuolar $\mathrm{H}+-$ translocating pyrophosphatase influencing grain chalkiness in rice. Nat Genet 46:398-404

Li XM, Chao DY, Wu Y, Huang XH, Chen K, Cui LG, Su L et al (2015) Natural alleles of a proteasome $\alpha 2$ subunit gene contribute to thermo tolerance and adaptation of African rice. Nat Genet 47:827-833

Li WT, Zhu ZW, Chern MS, Yin JJ, Yang C, Ran L, Cheng MP et al (2017) A natural allele of a transcription factor in rice confers broad-spectrum blast resistance. Cell 170:114-126

Li S, Tian YH, Wu K, Ye YF, Yu JP, Zhang JQ, Liu Q et al (2018a) Modulating plant growth-metabolism coordination for sustainable agriculture. Nature 560:595-600

Li Y, Xiao JH, Chen LL, Huang XH, Cheng ZK, Han B, Zhang Q et al (2018b) Rice functional genomics research: past decade and future. Mol Plant 11:1-22

Liang YT, Meng LJ, Lin XY, Cui YR, Pang YL, Xu JL, Li ZK (2018) QTL and QTL networks for cold tolerance at the reproductive stage detected using selective introgression in rice. PLoS ONE 13:e0200846

Lin CM, Koh S, Stacey G, Yu SM, Lin TY, Tsay YF (2000) Cloning and functional characterization of a constitutively expressed nitrate transporter gene, OsNRT1, from rice. Plant Physiol 122:379-388

Liu YQ, Wu H, Chen H, Liu YL, He J, Kang HY, Sun ZG et al (2015) A gene cluster encoding lectin receptor kinases confers broadspectrum and durable insect resistance in rice. Nat Biotechnol 33:301-305

Liu ZY, Zhu CS, Jiang Y, Tian YL, Yu J, An HZ, Tang WJ et al (2016) Association mapping and genetic dissection of nitrogen use efficiency-related traits in rice (Oryza sativa L.). Funct Int Genom $16: 323-333$

Liu JF, Chen J, Zheng XM, Wu FQ, Lin QB, Heng YQ, Tian P et al (2017) GW5 acts in the brassinosteroid signalling pathway to regulate grain width and weight in rice. Nat Plants 3:17043

Liu CT, Shujun O, Mao BG, Tang JY, Wang W, Wang HR, Cao SY et al (2018a) Early selection of bZIP73 facilitated adaptation of japonica rice to cold climates. Nat Commun 9:3302

Liu Q, Han RX, Wu K, Zhang JQ, Ye YF, Wang SS, Chen JF et al (2018b) G-protein $\beta \gamma$ subunits determine grain size through interaction with MADS-domain transcription factors in rice. Nat Commun 9:852

Luo LJ (2010) Breeding for water-saving and drought-resistance rice (WDR) in China. J Exp Bot 61:3509-3517

Lv Y, Guo ZL, Li XK, Ye HY, Li XH, Xiong LZ (2016) New insights into the genetic basis of natural chilling and cold shock tolerance in rice by genome-wide association analysis. Plant, Cell Environ 39:556-570

Ma Y, Dai XY, Xu YY, Luo W, Zheng XM, Zeng DL, Pan YJ et al (2015) COLD1 confers chilling tolerance in rice. Cell 160:1209-1221

Mahender A, Anandan A, Pradhan SK (2015) Early seedling vigour, an imperative trait for direct-seeded rice: an overview on physio-morphological parameters and molecular markers. Planta 241:1027-1050

Mahender A, Ali J, Prahalada GD, Sevilla MAL, Balachiranjeevi CH, Md J, Maqsood U et al (2019) Genetic dissection of developmental responses of agro-morphological traits under different doses of nutrient fertilizers using high-density SNP markers. PLoS ONE 14:e0220066

Mao DH, Xin YY, Tan YJ, Hu XJ, Bai JJ, Liu ZY, Yu YL et al (2019) Natural variation in the HAN1 gene confers chilling tolerance in rice and allowed adaptation to a temperate climate. Proc Natl Acad Sci USA 116:3494-3501

Mi JM, Li GW, Huang JY, Yu HH, Zhou FS, Zhang Q, Ouyang YD et al (2016) Stacking $S 5-n$ and $f 5-n$ to overcome sterility in indica-japonica hybrid rice. Theor Appl Genet 129:563-575

Peng SB, Huang JL, Zhong XH, Yang JC, Wang GH, Zou YB, Zhang FS et al (2002) Research strategy in improving fertilizer nitrogen use efficiency of irrigated rice in China. Agric Sci China 35:1095-1103

Peng B, Kong H, Li Y, Zhong M, Sun L, Gao GJ, Zhang QL et al (2014) OsAAP6 functions as an important regulator of grain protein content and nutritional quality in rice. Nat Commun 5:4847

Qiu XJ, Chen K, Lv WK, Ou XX, Zhu YJ, Xing DY, Yang LW et al (2017) Examining two sets of introgression lines reveals background independent and stably expressed QTL that improve grain appearance quality in rice (Oryza sativa L.). Theor Appl Genet 130:951-967

Qiu SQ, Lu Q, Yu HH, Ni XM, Zhang GY, He H, Xie WB et al (2018) The development and application of rice whole genome selection breeding platform. Chin Bull Life Sci 30:1120-1128

Redillas MC, Jeong JS, Kim YS, Jung H, Bang SW, Choi YD, Ha $\mathrm{SH}$ et al (2012) The overexpression of OsNAC9 alters the root architecture of rice plants enhancing drought resistance and grain yield under field conditions. Plant Biotechnol J 10:792-805

Ren ZH, Gao JP, Li LG, Cai XL, Huang W, Chao DY, Zhu MZ et al (2005) A rice quantitative trait locus for salt tolerance encodes a sodium transporter. Nat Genet 37:1141-1146

Sano Y, Katsumata M, Okuno K (1986) Genetic studies of speciation in cultivated rice. 5 . inter- and intraspecific differentiation in the waxy gene expression of rice. Euphytica 35:1-9

Si LZ, Chen JY, Huang XH, Gong H, Luo JH, Hou QQ, Zhou TY et al (2016) OsSPL13 controls grain size in cultivated rice. Nat Genet 48:447-456

Spindel JE, Begum H, Akdemir D, Collard B, Redoña E, Jannink JL, McCouch S (2016) Genome-wide prediction models that incorporate de novo GWAS are a powerful new tool for tropical rice improvement. Heredity 116:395-408

Sun HY, Qian Q, Wu K, Luo JJ, Wang SS, Zhang CW, Ma YF et al (2014) Heterotrimeric $G$ proteins regulate nitrogen-use efficiency in rice. Nat Genet 46:652-656

Sun WQ, Zhou QL, Yao Y, Qiu XJ, Xie K, Yu SB (2015) Identification of genomic regions and the isoamylase gene for reduced grain chalkiness in rice. PLoS ONE 10:e0122013

Sun C, Hu ZQ, Zheng TQ, Lu KC, Zhao Y, Wang W, Shi J et al (2016) RPAN: rice pan-genome browser for $\sim 3000$ rice genomes. Nucl Acids Res 45:597-605

Tian DS, Wang JX, Zeng X, Gu KY, Qiu CX, Yang XB, Zhou ZY et al (2014) The rice TAL effector-dependent resistance protein 
XA10 triggers cell death and calcium depletion in the endoplasmic reticulum. Plant Cell 26:497-515

Uga Y, Sugimoto K, Ogawa S, Rane J, Ishitani M, Hara N, Kitomi Y et al (2013) Control of root system architecture by DEEPER ROOTING 1 increases rice yield under drought conditions. Nat Genet 45:1097-1102

Veettil PC, Gupta, I, Ali J (2019) "GSR adoption and impacts in Punjab, India." Paper presented at the achieving improved income and livelihood by adopting Green Super Rice in Asia and Africa: the conclusion meeting of the Green Super Rice Project, Beijing, China. April 1-3, 2019

Wang F, Peng SB (2017) Yield potential and nitrogen use efficiency of China's super rice. J Int Agric 16:60345-60347

Wang BB, Wang HY (2017) IPAl: a new "green revolution" gene? Mol Plant 10:779-781

Wang SK, Wu K, Yuan QB, Liu XY, Liu ZB, Lin XY, Zeng RZ et al (2012a) Control of grain size, shape and quality by OSSPL16 in rice. Nat Genet 44:950-954

Wang WH, Kohler B, Cao FQ, Liu GW, Gong YY, Sheng S, Song QC et al (2012b) Rice DUR3 mediates high-affinity urea transport and plays an effective role in improvement of urea acquisition and utilization when expressed in Arabidopsis. New Phytol 193:432-444

Wang Q, Liu YQ, He J, Zheng XM, Hu JL, Liu YL, Dai HM et al (2014) STV11 encodes a sulphotransferase and confers durable resistance to rice stripe virus. Nat Commun 5:4768

Wang SK, Li S, Liu Q, Wu K, Zhang JQ, Wang SS, Wang Y et al (2015a) The OsSPL16-GW7 regulatory module determines grain shape and simultaneously improves rice yield and grain quality. Nat Genet 47:949-954

Wang WS, Fu BY, Ali J, Xu JL, Gao YM, Zheng TQ, Zhang F et al (2015b) Genome wide responses to selection and genetic networks underlying submergence tolerance in rice. Plant Genom $8: 1-13$

Wang YX, Xiong GS, Hu J, Jiang L, Hu Y, Xu J, Fang YX et al (2015c) Copy number variation at the $G L 7$ locus contributes to grain size diversity in rice. Nat Genet 47:944-948

Wang HB, Ye ST, Mou TM (2016) Molecular breeding of rice restorer lines and hybrids for brown planthopper (BPH) resistance using the Bph14 and Bph15 genes. Rice 9:53

Wang SS, Wu K, Qian Q, Liu Q, Li Q, Pan YY, Ye YF et al (2017a) Non-canonical regulation of SPL transcription factors by a human OTUB1-like deubiquitinase defines a new plant type rice associated with higher grain yield. Cell Res 27:1142-1156

Wang X, Li L, Yang Z, Zheng X, Yu S, Xu C, Zhu Z (2017b) Predicting rice hybrid performance using univariate and multivariate GBLUP models based on North Carolina mating design II. Heredity 118:302-310

Wang J, Zhou L, Shi H, Chern M, Yu H, Yi H, He M et al (2018a) A single transcription factor promotes both yield and immunity in rice. Science 361:1026-1028

Wang WS, Gao YM, Li ZK, Xu JL (2018b) “Green Super Rice” achieving sustainable development of agricultural production in Asian and African countries. Chin Bull Life Sci 30:1090-1099

Wang WS, Mauleon R, Hu ZQ, Chebotarov D, Tai SH, Wu ZC, Li M et al (2018c) Genomic variation in 3,010 diverse accessions of Asian cultivated rice. Nature 557:43-49

Wing RA, Purugganan MD, Zhang Q (2018) The rice genome revolution: from an ancient grain to Green Super Rice. Nat Rev Genet 19:505-517

Wu Y, Wang Y, Mi XF, Shan JX, Li XM, Xu JL, Lin HX (2016) The QTL GNP1 encodes GA20ox1, which increases grain number and yield by increasing cytokinin activity in rice panicle meristems. PLoS Genet 12:e1006386
Xia D, Zhou H, Liu RJ, Dan WH, Li PB, Wu B, Chen JX et al (2018) GL3.3, a novel QTL encoding a GSK3/SHAGGY-like kinase, epistatically interacts with GS3 to produce extra-long grains in rice. Mol Plant 11:754-756

Xiao C, Hu J, Ao YT, Cheng XM, Gao GJ, Zhang QL, He GC (2016) Development and evaluation of near-isogenic lines for brown planthopper resistance in rice cv. 9311. Sci Rep 6:38159

Xie WB, Wang GW, Yuan M, Yao W, Lv K, Zhao H, Yang M (2015) Breeding signatures of rice improvement revealed by a genomic variation map from a large germplasm collection. Proc Natl Acad Sci USA 112:5411-5419

Xing YZ, Zhang Q (2010) Genetic and molecular bases of rice yield. Annu Rev Plant Biol 61:421-442

Xu SZ, Zhu D, Zhang Q (2014) Predicting hybrid performance in rice using genomic best linear unbiased prediction. Proc Natl Acad Sci USA 111:12456-12461

Yang J, Mezmouk S, Baumgarten A, Buckler ES, Guill KE, McMullen MD, Mumm MH et al (2017) Incomplete dominance of deleterious alleles contributes substantially to trait variation and heterosis in maize. PLoS Genet 13:e1007019

Ying JZ, Ma M, Bai C, Huang XH, Liu JL, Fan YY, Song XJ (2018) $T G W 3$, a major QTL that negatively modulates grain length and weight in rice. Mol Plant 11:750-753

Yorobe JM, Ali J, Pede VO, Rejesusd RM, Velarde OP (2016) Yield and income effects of rice varieties with tolerance of multiple abiotic stresses: the case of green super rice (GSR) and flooding in the Philippines. Agric Econ 47:261-271

Yu HH, Xie WB, Li J, Zhou FS, Zhang Q (2014) A whole genome SNP array (RICE6K) for genomic breeding in rice. Plant Biotechnol J 12:28-37

Yu SB, Tang XX, Luo LJ (2016) Recent advances in rice functional genomics and Green Super Rice development. Chin Bull Life Sci 28:1287-1294

Zhang Q (2007) Strategies for developing Green Super Rice. Proc Natl Acad Sci USA 104:16402-16409

Zhang F, Zhang F, Huang LY, Cruz CV, Ali J, Xu JL, Zhou YL et al (2016) Overlap between signaling pathways responsive to Xanthomonas oryzae pv. oryzae infection and drought stress in rice introgression line revealed by RNA-Seq. J Plant Growth Regul $35: 345-356$

Zhang L, Yu H, Ma B, Liu GF, Wang JJ, Wang JM, Gao RC et al (2017a) A natural tandem array alleviates epigenetic repression of IPAI and leads to superior yielding rice. Nat Commun $8: 14789$

Zhang ZY, Li JJ, Pan YH, Li JH, Zhou L, Shi HL, Zeng YW et al (2017b) Natural variation in $C T B 4 a$ enhances rice adaptation to cold habitats. Nat Commun 8:14788

Zhang CP, Yu SB, Zhang Q (2018) Recent advances in Green Super Rice development. Chin Bull Life Sci 30:1083-1089

Zhang JY, Liu YX, Zhang N, Hu B, Jin T, Xu HR, Qin Y et al (2019) $N R T 1.1 B$ is associated with root microbiota composition and nitrogen use in field-grown rice. Nat Biotechnol 37:676-684

Zhao H, Yao W, Ouyang YD, Yang WN, Wang GW, Lian XM, Xing YZ et al (2015) RiceVarMap: a comprehensive database of rice genomic variations. Nucl Acids Res 43:1018-1022

Zhao Y, Huang J, Wang ZZ, Jing SL, Wang Y, Ouyang YD, Cai BD et al (2016) Allelic diversity in an NLR gene BPH9 enables rice to combat planthopper variation. Proc Natl Acad Sci USA 113:12850-12855

Zhou DG, Chen W, Lin ZC, Che HD, Wang CR, Li H, Yu RB et al (2016a) Pedigree-based analysis of derivation of genome segments of an elite rice reveals key regions during its breeding. Plant Biotechnol J 14:638-848

Zhou HJ, Wang LJ, Liu GF, Meng XB, Jing YH, Shu XL, Kong XL et al (2016b) Critical roles of soluble starch synthase SSIIIa and 
granule-bound starch synthase Waxy in synthesizing resistant starch in rice. Proc Natl Acad Sci USA 113:12844-12849

Zhou Q, Ju CX, Wang ZQ, Zhang H, Liu LJ, Yang JC, Zhang JH (2017a) Grain yield and water use efficiency of super rice under soil water deficit and alternate wetting and drying irrigation. $\mathbf{J}$ Int Agric 16:1028-1043

Zhou Y, Tao YJ, Tang DN, Wang J, Zhong J, Wang Y, Yuan QM et al (2017b) Identification of QTL associated with nitrogen uptake and nitrogen use efficiency using high throughput genotyped CSSLs in rice (Oryza sativa L.). Front Plant Sci 8:1166

Zhu XY, Xiong LZ (2013) Putative megaenzyme DWAl plays essential roles in drought resistance by regulating stressinduced wax deposition in rice. Proc Natl Acad Sci USA 110:17790-17795
Zhu YJ, Chen K, Mi XF, Chen TX, Ali J, Ye GY, Xu JL et al (2015) Identification and fine mapping of a stably expressed QTL for cold tolerance at the booting stage using an interconnected breeding population in rice. PLoS ONE 10:e0145704

Publisher's Note Springer Nature remains neutral with regard to jurisdictional claims in published maps and institutional affiliations. 